\title{
Convergence among the Sub-markets in Australian Regional Building Construction Sector
}

Junxiao Liu and Kerry A. London, (School of Architecture \& Building, Deakin University, Australia)

\begin{abstract}
Studies on market convergence are well considered in the literature. However, the majority of the previous research focused on housing markets and few studies have concentrated on construction markets. Owing to a simultaneously dramatic increase in the construction prices of the sub-markets in the building construction sector in Australia, this paper aims to identify the convergence among these markets, involving house construction market, otherresidential building construction market, and non-residential building construction market. To achieve it the Granger causality test and generalized response function depending on the vector error correction model with the quarterly data of Australia's eight states from 1998 to 2010 will be applied. Based upon the econometric tests, the price diffusion patterns among these construction markets have been identified. Research on the convergences of construction markets not only helps construction firms perform well in business operations and arbitrage activities, but also provides policy makers with useful information for enacting effective construction policies for national perspectives and approaches to infrastructure planning.
\end{abstract}

Keywords: Construction prices, Convergence, Vector error correction model

\section{Introduction}

Market convergence is one of the most popular research topics in the literature. This is because a comprehensive understanding of the situations of convergences allows business organisations to perform well in investments or arbitrage activities (Jiang et al., 2010), but also helps public sector policy makers effectively enact relevant policies for market adjustments (Bramley et al., 2007). Convergence generally defined in previous studies is the long-run causal or dynamic relationships between observed markets (Drake, 1995; Cook, 2003). As an important market indicator, prices are normally the primary variable for the research on convergence, such as house prices. Thus, construction prices will be the key variable in this study. The construction price concerned here is the output price that reflects the changes over time in the price of new construction outputs, and it can be measured by the output producer price indexes of construction industry, which are an economic indicator revealing the rate of change in the prices of buildings sold as they leave the production procedure (ABS, 2005; ABS, 2010a).

In Australia, the building construction sector consists of three sub-markets: house construction market, other-residential building construction (e.g. unit, flat and apartment) 
market, and non-residential building construction (e.g. hotel, shopping center, factory, school, hospital and cinema) market (ABS, 2006). Since 1998, the construction prices of these three markets in Australia have increased dramatically. Table 1 indicates the growth rates of the construction output producer price indexes (PPI) of the three markets aforementioned across the states between the September quarter 1998 (1998, Q3) and March quarter 2010 (2010, Q1).

\begin{tabular}{|c|c|c|c|c|c|c|c|c|}
\hline & NSW & VIC & QLD & SA & WA & TAS & NT & ACT \\
\hline $\begin{array}{c}\text { House } \\
\text { Construction }\end{array}$ & $47.9 \%$ & $51.0 \%$ & $70.3 \%$ & $63.3 \%$ & $97.1 \%$ & $72.8 \%$ & $84.2 \%$ & $66.6 \%$ \\
\hline $\begin{array}{c}\text { Other- } \\
\text { residential } \\
\text { construction }\end{array}$ & $54.3 \%$ & $44.3 \%$ & $51.2 \%$ & $58.6 \%$ & $86.8 \%$ & $64.7 \%$ & $76.5 \%$ & $59.8 \%$ \\
$\begin{array}{c}\text { Non- } \\
\text { residential } \\
\text { construction }\end{array}$ & $56.6 \%$ & $46.8 \%$ & $57.7 \%$ & $49.9 \%$ & $81.9 \%$ & $64.6 \%$ & $73.5 \%$ & $58.3 \%$ \\
\hline
\end{tabular}

Table 1: Growth rates of the construction output PPI (1998Q3-2010Q1), ABS, 2010b

Although these dramatic increases in construction prices can be triggered by a series of external economic or demographic factors, it is impossible to exclude the causation in a price convergence between these markets. This is because construction prices in different kinds of construction markets are not independent but interconnected. Skitmore et al. (2006) support this notion and maintain that inflations of construction prices in individual markets often diffuse to other markets because today's construction firms are diversified and their resources are employable across different market segments. Although there is a theoretical specification about construction price convergence, the empirical study in this field is sparse. The structure of this paper is quite conventional and includes a literature review on the studies which establish the context of this research. Then the methodology and data collection following the literature review will describe the econometric methods that will be applied for the analytical section and the data derived from Australian Bureau of Statistics. Finally, the Granger causality test and the generalised impulse response function depending on the vector error correction model (VECM) will be adapted to estimate the convergence between three sub-markets in Australia's regional building construction sector.

\section{Literature Review}

Convergence has been one of the most popular topics in academic research, particularly in the studies regarding housing, since the 1990s. Most of these studies focus on identifying the price diffusion or interactions in regional housing markets by a series of econometric techniques. This type of literature has contributed on the establishment of the theoretical system so called 'ripple effect' or 'convergence', whereby a price shock in a certain market will diffuse to other markets in a specified period and there is a long-run equilibrium relationship between the markets (Bramley et al., 2008).

The 'convergence' or 'ripple effect' studies originated from the house price research for British housing markets. From 1991 to 1997, a number of studies, such as Ashworth and Parker (1997), Giussani and Hadjimatheous (1991), Muellbauer and Murphy (1997) and 
Munro and Tu (1996), have contributed to the development of the concept of 'ripple effect'. In these studies, a similar structural time-series model is applied to test the convergence among the house prices of different regional housing markets in the UK. Apart from the studies aforementioned, Drake (1995) estimates the convergence between UK regional house prices by a different approach - the Kalman filter. All of these empirical studies suggest that there is a clear presence of convergence in the UK regional housing markets. At the end of the 1990s, Meen (1996; 1999) devises an innovative method with spatial effect to examine the existence of the 'ripple effect' in the UK regional housing market and he also explains this phenomenon from the causations of migration, equity transfer, spatial arbitrage and spatial pattern in the determinants of house prices.

Since the year 2000, the theory in regard to 'ripple effect' or 'convergence' has been systemised as more and more scholars contribute to the literature by developing different methodologies to test the 'ripple effect' and 'convergence'. For example, Cook (2003; 2005) applies the cointegration test and unit root tests to examine the convergence between regional house prices in the UK. Additionally, Stevenson (2004) adapts the Granger causality test based on the VECM to examine the convergence between the house prices of Ireland Republic and Northern Ireland. The empirical results of Stevenson (2004) suggest that there is a cross-border convergence existing in the housing markets of Ireland Republic and Northern Ireland, and 'the Northern Irish market is more linked with the housing market in the Republic than with the rest of the UK' (Stevenson, 2004, p. 301). Furthermore, the studies conducted by Holmes (2007) and Holmes and Grimes (2007) adopt the panel unit root test to examine the convergence of UK regional house prices, and the results indicate that the majority of UK regions exhibit house price convergence. Besides, a study undertaken by Chien (2010) proposes a two-break unit root test to test whether or not the regime changes have broken down the stability of housing 'ripple effect' in Taiwan. The findings of Chien's (2010) study support the existence of the 'ripple effect' in Taiwan and further demonstrate that changes in policies can trigger structural breaks of regional house prices.

In Australia, the empirical research related to 'ripple effect' or convergence is more recent, (Luo et al., 2007; Liu et al., 2008). These two studies use the error correction model (ECM) and vector autoregression model (VAR) respectively to identify the causal and dynamic relationships between the house prices of Australian regional housing markets. The results generated by the Engle-Granger-based cointegration test and a VAR model help Luo et al. (2007) and Liu et al. (2008) to identify a price diffusion pattern of the housing markets of eight state capital cities in Australia. Furthermore, the research of Liu et al. (2009) estimates the interactions between the housing markets of eight state capital cities in Australia using the variance decomposition on the basis of a VAR model. This study focuses on the house price growth rate rather than the house price level, and the findings suggest the changes in the house prices in Sydney and Melbourne cause the movements in the house prices of other state capital cities.

Liu, J and London, K A (2010) 'Convergence among the sub-markets in Australian regional building construction sector', Australasian Journal of Construction Economics and Building, 10 (4) 11-33 
It can be identified from the studies aforementioned that the empirical research on 'ripple effect' and 'convergence' is primarily concerned with regional housing markets. However, the work commenced by Ho et al. (2008) estimates the price convergence of different types of housing markets in Hong Kong. In this study, Hong Kong's housing market is not viewed as an entity but several sub-markets defined as Class A (under 40 square meters), Class B (4060 square meters), Class $C$ (70-99.9 square meters) and Class $D$ (100 square meters and above). The results based on the Granger causality test strongly indicate that a 'ripple effect' exists in the sub-markets in Hong Kong housing market (Ho et al., 2008).

Although a large number of empirical research emphasise market convergence, the study with regard to construction market within this field is sparse. Jiang et al. (2010) identifies this point and investigates the long-run relationship between house construction markets across Australia's six states and two territories. The empirical evidences encourage Jiang et al. (2010) to identify the price interaction pattern within regional context, in which Victoria and New South Wales are of the states that are more sensitive to the construction price changes in other states. However, the study of Jiang et al. (2010) only focuses on the causal links of house construction market across six states and two territories in Australia but not on the cross-market interactions among all sub-markets in Australian building construction sector.

This literature review has presented an overview of previous studies in relation to the 'ripple effect' and convergence (Chien, 2008; Cook, 2003, 2005; Drake, 1995; Giussani and Hadjimatheous, 1991; Ho et al., 2008; Holmes, 2007; Holmes and Grimes, 2007; Liu et al., 2008; Liu et al., 2009; Luo et al., 2007; Meen, 1999; Muellbauer and Murphy, 1997; Munro and Tu, 1996; Parker, 1997; and Stevenson, 2004). Jiang et al. (2010) are novel in their approach unlike the other studies and they test the convergence for regional construction markets. Thus, it is identified from the literature review that the analysis on convergence is mainly concerned with housing markets but is lacking for construction markets, especially for the sub-market convergence within the framework building regional construction sector. This provides an opportunity for further study.

\section{Methodology}

The sections of introductions and literature review have demonstrated that convergence is a long-run causal and dynamic relationship between variables. Therefore, the Granger causality test and the generalized impulse response function depending on the vector error correction models are the ideal tools for this study. These two econometric methods can help to identify the causal linkage and dynamic mutual influences between the variables with long-run equilibrium relationship (Hui \& Yue, 2006).

\section{Vector Error Correction Model (VECM)}

The vector error correction model is proposed by Engle and Granger (1987) through integrating the autoregressive and error correction representations into co-integrated systems. In short, the VECM is a vector autoregressive (VAR) model with co-integrated restriction and error correction term. One of the purported advantages of recognizing 
cointegration in the autoregressive system is the improvement in forecasting performance (Engle \& Yoo, 1987). The form of the VECM $(p)$ can be written as follows.

$$
\begin{aligned}
& \Delta Y_{t}=\alpha \beta^{\prime} Y_{t-1}+\sum_{i=1}^{p-1} \Gamma_{i} \Delta Y_{t-i}{ }^{+} \varepsilon_{t} \\
& \Delta Y_{t}=\alpha e^{p c m_{t-1}}+\sum_{i=1}^{p-1} \Gamma_{i} \Delta Y_{t-i}{ }^{+} \varepsilon_{t}
\end{aligned}
$$

where $\Delta Y_{t-1}$ stands for a vector in difference level with $\mathrm{k}$ dimensions; $e c m_{t-1}=\beta^{\prime} Y_{t-1}$ denotes the error correction term, which reflects the long-run equilibrium relationship between variables; $\Gamma_{i}$ is the coefficient matrices; and $\varepsilon_{t}$ is a k-dimensional vector of error term. Due to the integration of autoregression and cointegration, the establishment of the VECM relies on two other simple tests, unit root test and cointegration test.

\section{Granger Causality Test}

The Granger causality test is a technique proposed by Granger (1969) in the 1960s and it is used to examine whether lagged values of a time-series variable $X$ have explanatory power in the movement of the other time-series variable $Y$. If the changes in the $Y$ can be explained by the lagged information of $X$, it is concluded that $X$ Granger causes $Y$.

The test of the Granger causality is able to be based on simple $F$ tests in the reduced-form VAR or VEC models. As suggested by Greene (2000) and Gao (2009), a bivariate reducedform VAR $(p)$ displayed as Equation (3) is an appropriate model to explain the Granger causality test depending on the VAR.

$$
\left(\begin{array}{l}
Y_{t} \\
X_{t}
\end{array}\right)=\left(\begin{array}{l}
a_{10} \\
a_{20}
\end{array}\right)+\left(\begin{array}{ll}
a_{11}^{(1)} & a_{12}^{(1)} \\
& \\
a_{21}^{(1)} & a_{22}^{(1)}
\end{array}\right)\left(\begin{array}{l}
Y_{t-1} \\
X_{t-1}
\end{array}\right)+\left(\begin{array}{ll}
a_{11}^{(2)} & a_{12}^{(2)} \\
a_{21}^{(2)} & a_{22}^{(2)}
\end{array}\right)\left(\begin{array}{l}
Y_{t-2} \\
X_{t-2}
\end{array}\right)+\cdots+\left(\begin{array}{ll}
a_{11}^{p} & a_{12}^{p} \\
a_{21}^{p} & a_{21}^{p}
\end{array}\right)\left(\begin{array}{l}
Y_{t-p} \\
X_{t-p}
\end{array}\right)+\left(\begin{array}{l}
\varepsilon_{1 t} \\
\varepsilon_{2 t}
\end{array}\right)
$$

If and only if coefficient $a_{12}^{(q)}=0$ in coefficient matrices, the lagged values of variable $X$ have no explanatory power for $Y$, implying that $X$ can not Granger cause $Y$ and it is exogenous to the system. Accordingly, the most appropriate solution for estimating the Granger causation is applying the $F$-test to examine the following joint hypothetical testing.

$$
\begin{aligned}
& H_{0}: a_{a 2}^{(q)}=0, q=1,2, \cdots, p \\
& H_{1} \text { : There is at least one } q \text { in the system causing } a_{12}^{(q)} \neq 0
\end{aligned}
$$

The statistics of the testing are indicated as follows: 


$$
S_{1}=\frac{\left(R S S_{0}-R S S_{1}\right) / p}{R S S_{1} /(T-2 p-1)} \sim F(p, T-2 p-1)
$$

where $S_{i}$ follows the F-distribution; $R S S_{1}$ denotes the residual sum of squares of the $Y$ equation in (3), and $R S S_{0}$ is the residual sum of squares of the $Y$ equation without variable $X$. The $R S S_{1}$ and $R S S_{0}$ are also able to be written as follows.

$R S S_{1}=\sum \hat{\varepsilon}_{1 t}^{2}$

$R S S_{1}=\sum \hat{\widetilde{\varepsilon}}_{1 t}^{2}$

If $S_{1}$ is larger than the critical values of the $F$-distribution, then the null hypothesis $\left(H_{0}\right)$ of the joint hypothetical testing above will be rejected, implying that $X$ Granger cause $Y$. Otherwise, the null hypothesis will be accepted: $X$ can not Granger cause $Y$.

Since the 1990s, some research attempts to test the Granger causality within a vector autoregressive system with the cointegration because there is an existence of misspecifications of the reduced-form VARs when the observed variables are co-integrated. These studies involved Toda and Yamamoto (1995), Yamamoto and Kurozumi (2006) and Rajaguru and Abeysinghe (2008). As a result, the Granger causality test can be run under the VECM framework.

\section{Generalized Impulse Response Function (GIRF)}

The impulse response function (IRF) is utilised to trace out the systematically dynamic effect of a shock of the error term of an endogenous variable to other variables in the VAR or VEC models. It is one of the core analytical components of the vector autoregressive systems. Koop et al. (1996) develop the traditional IRF and create the generalized impulse response function. A summary of key equation is now explained. To understand the GIRF, a VAR $(p)$ must be presented first.

$$
X_{t}=\Phi D_{t}+\sum_{i=1}^{k} \prod_{i} X_{t-1}+\varepsilon_{t} \quad t=1, \ldots, T
$$

where $X_{t}$ stands for a vector with $p$ dimensions; $D_{t}$ is a vector with deterministic variables; $\varepsilon_{t}$ denotes a vector of error term with $p$ dimensions and it is assumed to be independent and identically distributed with zero mean and positive definite covariance matrices $\Omega$.

The $h$-steps ahead forecast error for $X_{t}$ is written as Equation (8).

$$
X_{t+h}-E\left[X_{t+h} \mid \mathrm{II}\right]=\sum_{j=0}^{h-1} C_{j} \varepsilon_{t+h-j}
$$


Here $\mathrm{II}_{t}$ is a set of information, which incorporates all lagged values as well as the $t$-period values of $X_{t}$ and the entire time path for $D_{t}$. The $C_{j}$ is $p^{*} p$ matrices with a condition that $C_{0}=I_{p}$. Therefore,

$$
C_{j}=\sum_{i=1}^{\min k, j} \prod_{i} C_{j-i}, \quad j \geq 1
$$

As a result, all $C_{j}$ matrices are able to be determined by the matrices $\prod$. The GIRF, therefore, can be defined as:

$$
G I_{x}\left(h, \delta, \mathrm{II}_{t-1}\right)=E\left|X_{t+h}\right| \boldsymbol{\varepsilon}_{t}=\delta, \mathrm{II}_{t-1} \mid-E\left[X_{t+h} \mid \mathrm{II}_{t-1}\right]
$$

where $\delta$ stands for a some known vector, implying that:

$$
G I_{x}\left(h, \delta, \mathrm{II}_{t-1}\right)=C_{h} \delta
$$

Based upon Equation (11), it can be summarized that $\delta$ is a key issue for determining the time for any GIRF. In order to simplify the calculation of the function, shocking one element $\left(\varepsilon_{j t}=\delta_{j}\right)$ instead of shocking all components of $\varepsilon_{t}$ is an appropriate alternative. Hence the GIRF can be defined again by:

$$
G I_{x}\left(h, \delta, \mathrm{II}_{t-1}\right)=E\left|X_{t+h}\right| \boldsymbol{\varepsilon}_{j t}=\delta_{j}, \mathrm{II} \mathrm{I}_{t-1} \mid-E\left[X_{t+h} \mid \mathrm{II}_{t-1}\right]
$$

Assuming that $\delta_{j}=\sqrt{w_{j j}}, \varepsilon_{j t}$ is a standard deviation, and $\varepsilon_{t}$ follows Gaussian distribution. Then,

$$
E\left[\varepsilon_{t} \mid \mathcal{E}_{j t}=\sqrt{w_{j j}}\right]=\Omega e_{j} w_{j j}^{-1 / 2}
$$

where $e_{j}$ stands for the $j$-th column of $I_{p}$. As a result, the GIRF can be viewed as:

$$
G I_{x}\left(h, \sqrt{w_{j j}}, \mathrm{II} t_{t-1}\right)=C_{h} \Omega e_{j} w_{i j}^{-1 / 2}
$$

The Equation (14) measures the response of $X_{t+h}$ to a standard deviation of $\varepsilon_{j t .}$ In this kind of response, the correlation between $\varepsilon_{j t}$ and $\varepsilon_{i t}$ has been considered. 


\section{Data Collection and Description}

The output PPI of Australia's three construction markets in building construction sector, including house construction output PPI (HPPI), other-residential building construction output PPI (ORBPPI) and non-residential building construction output PPI (NRBPPI), will be the data used in this study. This type of index in Australia is compiled and published by the Australian Bureau of Statistics. As mentioned in the introduction, the construction industry output PPI measures the changes in prices of the outputs of selected construction industry classes.

Figure 1, 2 and 3 indicate the movements of construction industry output PPI for the three markets aforementioned in Australia's six states and two territories from 1998Q3 to 2010Q1. All of these figures indicate that the construction output PPI in state level maintained an upward trend during the sample period. The overall average growth rates of construction output PPI of the submarkets within building construction sector in every state were more than $47 \%$. In the group of Western Australia and Northern Territory, the changes in the construction output PPI were the most apparent. Figure 1, 2 and 3 illustrate that the construction output PPI of Western Australia between 1998Q3 and 2010Q1 increased from 98.9 to 194.9 in house construction market, 99.2 to 185.3 in other-residential building construction market, and 99.4 to 180.8 in non-residential building construction market. In Northern Territory, the construction output PPI of the three markets increased to about 176.0 from no more than 100.0. However, the changes in the construction output PPI in New South Wales and Victoria were the least evident. In New South Wales, the construction output PPI rose to $145.8,151.5$ and 153.3 from $98.6,98.2$ and 97.9 respectively in the three markets. In addition, Victoria's construction output PPI increased by 147.1, 141.8, and 145.0 from the level of 98.0 during the period under study. Regarding the group composed of Queensland, South Australia, Tasmania, and Australian Capital Territory, the growth rates of the construction output PPI were similar, as much as $60 \%$.

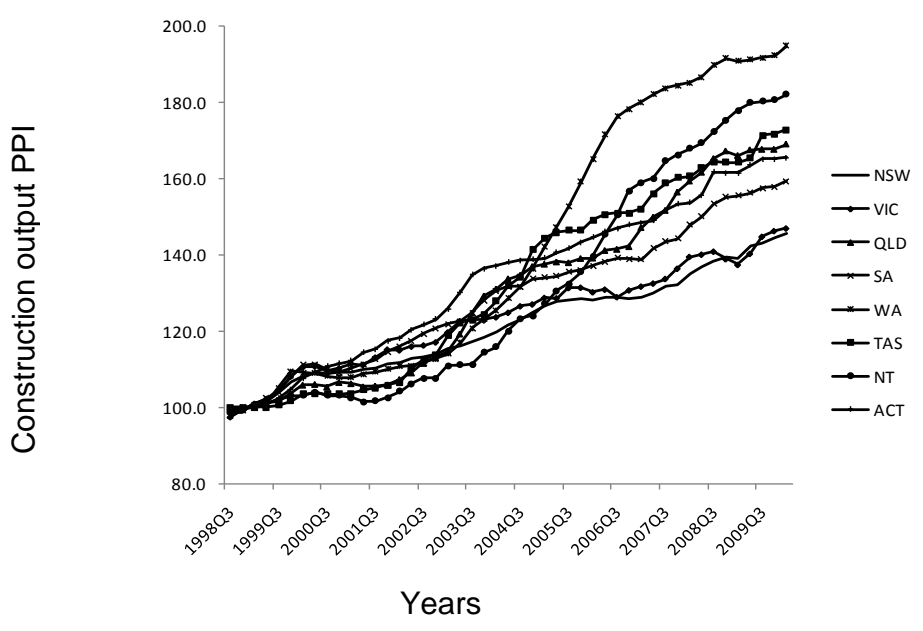

Figure 1: The output PPI of house construction in Australia

Liu, J and London, K A (2010) 'Convergence among the sub-markets in Australian regional building construction sector', Australasian Journal of Construction Economics and Building, 10 (4) 11-33 


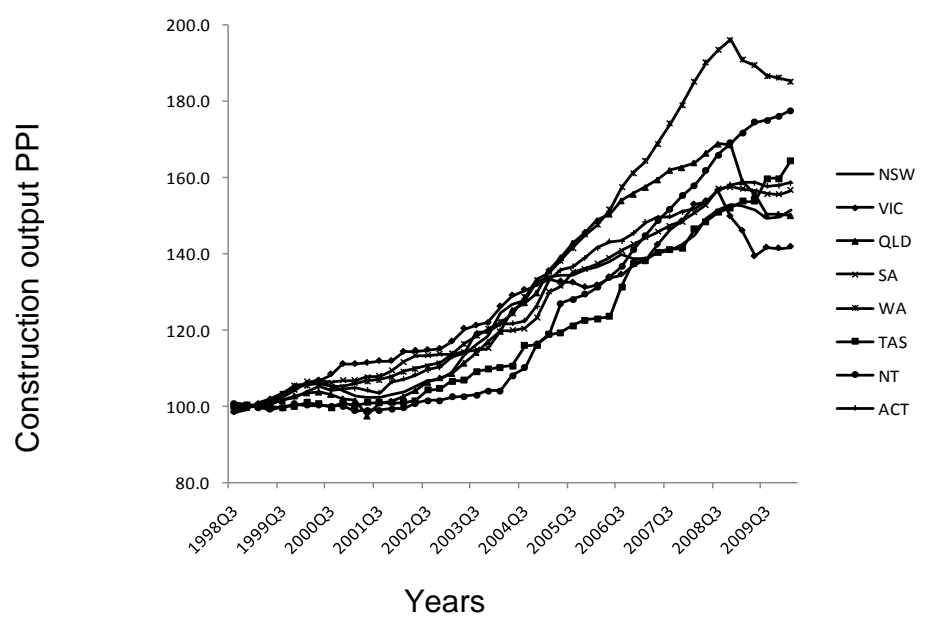

Figure 2: The output PPI of other-residential building construction in Australia

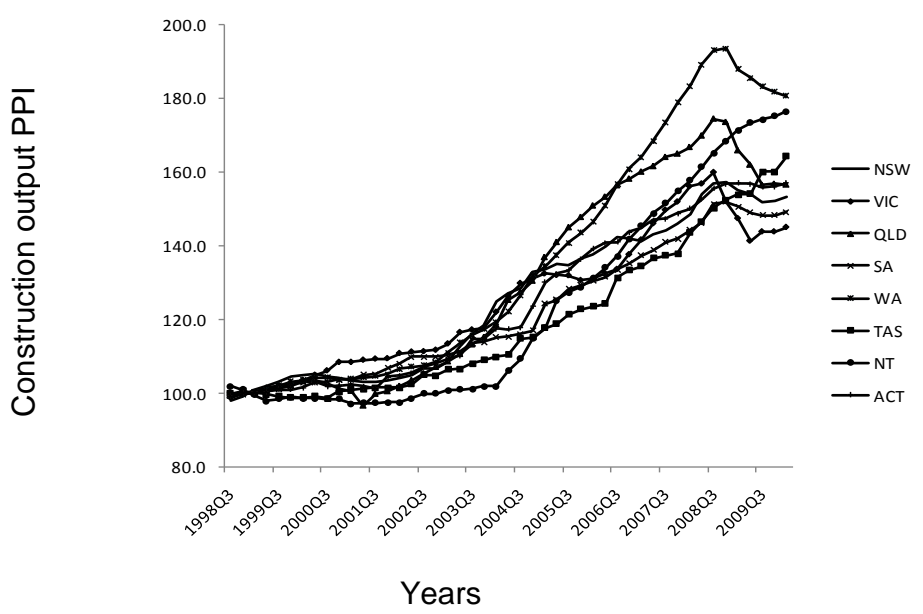

Figure 3: The output PPI of non-residential building construction in Australia

The identity of simultaneity of the increases in the construction prices of three different markets during recent decade allows to be inferred that there should be an interaction of construction price existing in building construction sector in Australia. In the following analytical section, two econometric methods discussed in the methodology will be set up to pursue this kind of dynamics.

\section{Analysis and Discussion}

The prerequisite of the VAR or VEC model is the data imported must be stationary. Otherwise, a spurious regression will be triggered. Thus, testing the stability of the timeseries data is the first procedure of the analysis on the basis of the VAR or VECM. Table 1 illustrates the unit root test results of the construction industry output PPI of all sub-markets in building construction sector in Australian six states and two territories. The results suggest that such variables are not stationary at the level form but stationary after the first difference at the $1 \%$ and $5 \%$ significance levels. In summary, all data are $I(1)$ denoting that the timeseries data integrated at the first difference level. 


\begin{tabular}{|c|c|c|c|c|c|}
\hline \multirow[t]{2}{*}{ Variables } & \multicolumn{2}{|r|}{ Level } & \multicolumn{2}{|c|}{ First Difference } & \multirow[t]{2}{*}{ Results } \\
\hline & $\begin{array}{c}\text { Model } \\
\text { specification } \\
\text { (lags) }\end{array}$ & $\begin{array}{l}\text { PP Test Statistics } \\
(5 \%, 1 \% \text { sig. level) }\end{array}$ & $\begin{array}{l}\text { Model } \\
\text { specification } \\
\text { (lags) }\end{array}$ & $\begin{array}{l}\text { PP Test Statistics } \\
(5 \%, 1 \% \text { sig. level) }\end{array}$ & \\
\hline In(HPPI_NSW) & $\begin{array}{l}\text { Intercept \& } \\
\text { Trend (2) }\end{array}$ & $-0.72(-3.51,-4.17)$ & None (2) & $-2.64(-1.95,-2.62)$ & $I(1)^{* \star *}$ \\
\hline In(HPPI_VIC) & $\begin{array}{l}\text { Intercept \& } \\
\text { Trend (2) }\end{array}$ & $-3.25(-3.51,-4.17)$ & None (2) & $-3.74(-1.95,-2.62)$ & $I(1)^{* \star *}$ \\
\hline In(HPPI_QLD) & $\begin{array}{l}\text { Intercept \& } \\
\text { Trend (2) }\end{array}$ & $-2.02(-3.51,-4.17)$ & None (2) & $-2.26(-1.95,-2.62)$ & $I(1)^{\star *}$ \\
\hline In(HPPI_SA) & $\begin{array}{l}\text { Intercept \& } \\
\text { Trend (2) }\end{array}$ & $-2.69(-3.51,-4.17)$ & None (2) & $-2.49(-1.95,-2.62)$ & $I(1)^{\star \star}$ \\
\hline In(HPPI_WA) & $\begin{array}{l}\text { Intercept \& } \\
\text { Trend (2) }\end{array}$ & $-1.35(-3.51,-4.17)$ & None (2) & $-2.97(-1.95,-2.62)$ & $I(1)^{* * *}$ \\
\hline In(HPPI_TAS) & $\begin{array}{l}\text { Intercept \& } \\
\text { Trend (2) }\end{array}$ & $-1.84(-3.51,-4.17)$ & None (2) & $-2.74(-1.95,-2.62)$ & $I(1)^{* \star \star}$ \\
\hline In(HPPI_NT) & $\begin{array}{l}\text { Intercept \& } \\
\text { Trend (2) }\end{array}$ & $-1.91(-3.51,-4.17)$ & None (2) & $-2.19(-1.95,-2.62)$ & $I(1)^{* *}$ \\
\hline In(HPPI_ACT) & $\begin{array}{l}\text { Intercept \& } \\
\text { Trend (2) }\end{array}$ & $-1.09(-3.51,-4.17)$ & None (2) & $-2.33(-1.95,-2.62)$ & $I(1)^{\star \star}$ \\
\hline In(ORBPPI_NSW) & $\begin{array}{l}\text { Intercept \& } \\
\text { Trend (2) }\end{array}$ & $-1.49(-3.51,-4.17)$ & None (2) & $-2.80(-1.95,-2.62)$ & $I(1)^{* * *}$ \\
\hline In(ORBPPI_VIC) & $\begin{array}{l}\text { Intercept \& } \\
\text { Trend (2) }\end{array}$ & $-1.20(-3.51,-4.17)$ & None (2) & $-4.02(-1.95,-2.62)$ & $I(1)^{* * *}$ \\
\hline In(ORBPPI_QLD) & $\begin{array}{l}\text { Intercept \& } \\
\text { Trend (2) }\end{array}$ & $-0.77(-3.51,-4.17)$ & None (2) & $-3.38(-1.95,-2.62)$ & $I(1)^{* \star *}$ \\
\hline In(ORBPPI_SA) & $\begin{array}{l}\text { Intercept \& } \\
\text { Trend (2) }\end{array}$ & $-1.67(-3.51,-4.17)$ & None (2) & $-3.30(-1.95,-2.62)$ & $I(1)^{\star \star \star}$ \\
\hline In(ORBPPI_WA) & $\begin{array}{l}\text { Intercept \& } \\
\text { Trend (2) }\end{array}$ & $-1.62(-3.51,-4.17)$ & None (2) & $-1.98(-1.95,-2.62)$ & $I(1)^{\star *}$ \\
\hline In(ORBPPI_TAS) & $\begin{array}{l}\text { Intercept \& } \\
\text { Trend (2) }\end{array}$ & $-1.93(-3.51,-4.17)$ & None (2) & $-4.42(-1.95,-2.62)$ & $I(1)^{\star \star *}$ \\
\hline In(ORBPPI_NT) & $\begin{array}{l}\text { Intercept \& } \\
\text { Trend (2) }\end{array}$ & $-2.20(-3.51,-4.17)$ & None (2) & $-2.65(-1.95,-2.62)$ & $I(1)^{* * *}$ \\
\hline In(ORBPPI_ACT) & $\begin{array}{l}\text { Intercept \& } \\
\text { Trend (2) }\end{array}$ & $-1.66(-3.51,-4.17)$ & None (2) & $-3.49(-1.95,-2.62)$ & $I(1)^{* * *}$ \\
\hline In(NRBPPI_NSW) & $\begin{array}{l}\text { Intercept \& } \\
\text { Trend (2) }\end{array}$ & $-1.41(-3.51,-4.17)$ & None (2) & $-2.73(-1.95,-2.62)$ & $I(1)^{* * *}$ \\
\hline In(NRBPPI_VIC) & $\begin{array}{l}\text { Intercept \& } \\
\text { Trend (2) }\end{array}$ & $-1.57(-3.51,-4.17)$ & None (2) & $-3.61(-1.95,-2.62)$ & $I(1)^{* * *}$ \\
\hline In(NRBPPI_QLD) & $\begin{array}{c}\text { Intercept \& } \\
\text { Trend (2) }\end{array}$ & $-1.04(-3.51,-4.17)$ & None (2) & $-3.05(-1.95,-2.62)$ & $I(1)^{* * *}$ \\
\hline In(NRBPPI_SA) & $\begin{array}{l}\text { Intercept \& } \\
\text { Trend (2) }\end{array}$ & $-2.07(-3.51,-4.17)$ & None (2) & $-3.87(-1.95,-2.62)$ & $I(1)^{* * *}$ \\
\hline In(NRBPPI_WA) & $\begin{array}{l}\text { Intercept \& } \\
\text { Trend (2) }\end{array}$ & $-1.63(-3.51,-4.17)$ & None (2) & $-2.59(-1.95,-2.62)$ & $I(1)^{\star *}$ \\
\hline In(NRBPPI_TAS) & $\begin{array}{l}\text { Intercept \& } \\
\text { Trend (2) }\end{array}$ & $-2.06(-3.51,-4.17)$ & None (2) & $-4.22(-1.95,-2.62)$ & $I(1)^{\star \star \star}$ \\
\hline In(NRBPPI_NT) & $\begin{array}{l}\text { Intercept \& } \\
\text { Trend (2) }\end{array}$ & $-2.61(-3.51,-4.17)$ & None (2) & $-2.14(-1.95,-2.62)$ & $I(1)^{* *}$ \\
\hline In(NRBPPI_ACT) & $\begin{array}{l}\text { Intercept \& } \\
\text { Trend (2) }\end{array}$ & $-1.85(-3.51,-4.17)$ & None (2) & $-3.65(-1.95,-2.62)$ & $I(1)^{\star \star \star}$ \\
\hline
\end{tabular}

Table 2: PP tests of the variables for 1998Q3 - 2010Q1

Notes: The PP Tests, which are the unit root test similar to the ADF Tests, contain three kinds of model specification: only intercept, trend and intercept, and no trend and no intercept. ${ }^{* *}$ and ${ }^{* * *}$ denote the $95 \%$ and $99 \%$ significance level.

One of the challenges other than stationary test in the VECM is testing whether or not a long-run equilibrium relationship exists in between variables. In other words, detecting the

Liu, J and London, K A (2010) 'Convergence among the sub-markets in Australian regional building construction sector', Australasian Journal of Construction Economics and Building, 10 (4) 11-33 
cointegration is the other necessary step for constructing the VECM. Hence, the multivariate cointegration test (JJ test) proposed by Johansen and Juselius (1990) is an appropriate method to fulfill this requirement. There are five models of the $\mathrm{JJ}$ test. Model 1 (M1) represents the observed time series has no deterministic trend and the cointegration equation (CE) has no intercept and trend. Model 2 (M2) is the model in which the observed series has no deterministic trend but the CE has an intercept but no trend. Model 3 (M3) is the model where the observed time series has linear trend and the CE has an intercept but no trend. Model 4 (M4) denotes the observed time series has linear trend and the CE has both intercept and trend. Model 5 (M5) represents the observed time series has quadratic data trend and the CE has an intercept and a trend. Table 3 presents the $\mathrm{JJ}$ test result summary of the three construction markets of each state in Australia. The results indicates that there are long-run equilibrium relationships between construction output producer price indexes of three different construction markets in eight states of Australia, implying that the data employed in this study is suitable for formulating the VECM. The number of cointegration for the VECM construction will be based on the results of Table 3.

\begin{tabular}{|c|c|c|c|c|}
\hline States & Lagged difference & $\begin{array}{c}\text { Model } \\
\text { specification }\end{array}$ & $\begin{array}{c}\text { Results } \\
\text { (Trace test) }\end{array}$ & $\begin{array}{c}\text { Results } \\
\text { (Max-eigenvalue test) }\end{array}$ \\
\hline NSW & 6 & M3 & 2 & 2 \\
\hline VIC & 5 & M3 & 1 & 1 \\
\hline QLD & 4 & M3 & 1 & 1 \\
\hline SA & 9 & M3 & 1 & 1 \\
\hline WA & 9 & M3 & 2 & 2 \\
\hline TAS & 7 & M3 & 2 & 1 \\
\hline NT & 8 & M3 & 1 & 2 \\
\hline ACT & 9 & M3 & 2 & 2 \\
\hline
\end{tabular}

Table 3: Summary of the JJ test results of construction output PPI

Once the VEC models are constructed, the Granger causality test and generalized impulse response function will be selected to examine the causal and dynamic relationships between variables. Table 4 and Figure 4 respectively presented the summary of the Granger causality tests and causal relationships among house construction output PPI, other-residential building construction output PPI, and non-residential building construction output PPI across six states and two territories of Australia. In Table 4, the $P$-values under 0.05 indicate that the null hypothesis ( $X$ does not Granger cause $Y$ ) referred in the Methodology will be rejected. In other words, there is a causal relationship between two variables. From Table 4 and Figure 4, it can be firstly identified that changes in the construction prices of house construction markets Granger cause the movements in the construction prices of otherresidential building in all states in Australia. In New South Wales, Western Australia, and Northern Territory, the causal relationships between house construction prices and otherresidential building construction prices are bilateral, implying that increases or decreases in 
other-residential building construction prices in such states also Granger cause the changes in house construction prices.

\begin{tabular}{|c|c|c|c|c|}
\hline States & Directions & Chi-square & $P$ values & Results \\
\hline \multirow{6}{*}{$\begin{array}{l}\text { New South } \\
\text { Wales }\end{array}$} & $\mathrm{HPPI} \rightarrow$ ORBPPI & 25.42 & 0.00 & Y \\
\hline & $\mathrm{HPPI} \rightarrow \mathrm{NRBPPI}$ & 30.43 & 0.00 & $\mathrm{Y}$ \\
\hline & ORBPPI $\rightarrow$ HPPI & 16.17 & 0.01 & $Y$ \\
\hline & ORBPPI $\rightarrow$ NRBPPI & 15.89 & 0.01 & Y \\
\hline & NRBPPI $\rightarrow$ HPPI & 8.89 & 0.18 & $\mathrm{~N}$ \\
\hline & NRBPPI $\rightarrow$ ORBPPI & 16.43 & 0.01 & $\mathrm{Y}$ \\
\hline \multirow[t]{6}{*}{ Victoria } & HPPI $\rightarrow$ ORBPPI & 10.55 & 0.06 & Y \\
\hline & $\mathrm{HPPI} \rightarrow \mathrm{NRBPPI}$ & 12.99 & 0.02 & $\mathrm{Y}$ \\
\hline & ORBPPI $\rightarrow$ HPPI & 1.28 & 0.94 & $\mathrm{~N}$ \\
\hline & ORBPPI $\rightarrow$ NRBPPI & 9.18 & 0.09 & $Y$ \\
\hline & NRBPPI $\rightarrow$ HPPI & 2.45 & 0.78 & $\mathrm{~N}$ \\
\hline & NRBPPI $\rightarrow$ ORBPPI & 4.74 & 0.45 & $\mathrm{~N}$ \\
\hline \multirow[t]{6}{*}{ Queensland } & HPPI $\rightarrow$ ORBPPI & 15.08 & 0.00 & Y \\
\hline & $\mathrm{HPPI} \rightarrow \mathrm{NRBPPI}$ & 14.63 & 0.01 & $Y$ \\
\hline & ORBPPI $\rightarrow$ HPPI & 3.12 & 0.54 & $\mathrm{~N}$ \\
\hline & ORBPPI $\rightarrow$ NRBPPI & 19.31 & 0.00 & $Y$ \\
\hline & NRBPPI $\rightarrow \mathrm{HPPI}$ & 2.47 & 0.65 & $\mathrm{~N}$ \\
\hline & NRBPPI $\rightarrow$ ORBPPI & 15.20 & 0.00 & $Y$ \\
\hline \multirow{6}{*}{$\begin{array}{c}\text { South } \\
\text { Australia }\end{array}$} & HPPI $\rightarrow$ ORBPPI & 20.78 & 0.01 & $Y$ \\
\hline & $\mathrm{HPPI} \rightarrow \mathrm{NRBPPI}$ & 17.12 & 0.05 & $Y$ \\
\hline & ORBPPI $\rightarrow$ HPPI & 7.67 & 0.57 & $\mathrm{~N}$ \\
\hline & ORBPPI $\rightarrow$ NRBPPI & 17.83 & 0.04 & $Y$ \\
\hline & NRBPPI $\rightarrow \mathrm{HPPI}$ & 7.38 & 0.60 & $\mathrm{~N}$ \\
\hline & NRBPPI $\rightarrow$ ORBPPI & 33.57 & 0.00 & $Y$ \\
\hline \multirow{6}{*}{$\begin{array}{l}\text { Western } \\
\text { Australia }\end{array}$} & $\mathrm{HPPI} \rightarrow$ ORBPPI & 27.88 & 0.00 & $Y$ \\
\hline & $\mathrm{HPPI} \rightarrow \mathrm{NRBPPI}$ & 18.23 & 0.03 & Y \\
\hline & ORBPPI $\rightarrow$ HPPI & 16.69 & 0.05 & Y \\
\hline & ORBPPI $\rightarrow$ NRBPPI & 22.88 & 0.01 & Y \\
\hline & $\mathrm{NRBPPI} \rightarrow \mathrm{HPPI}$ & 18.36 & 0.03 & $Y$ \\
\hline & NRBPPI $\rightarrow$ ORBPPI & 62.02 & 0.03 & Y \\
\hline \multirow[t]{6}{*}{ Tasmania } & $\mathrm{HPPI} \rightarrow$ ORBPPI & 19.16 & 0.01 & Y \\
\hline & $\mathrm{HPPI} \rightarrow \mathrm{NRBPPI}$ & 17.20 & 0.02 & $Y$ \\
\hline & ORBPPI $\rightarrow$ HPPI & 5.61 & 0.59 & $\mathrm{~N}$ \\
\hline & ORBPPI $\rightarrow$ NRBPPI & 2.18 & 0.95 & $\mathrm{~N}$ \\
\hline & NRBPPI $\rightarrow$ HPPI & 4.70 & 0.70 & $\mathrm{~N}$ \\
\hline & NRBPPI $\rightarrow$ ORBPPI & 19.59 & 0.01 & $Y$ \\
\hline \multirow{6}{*}{$\begin{array}{l}\text { Northern } \\
\text { Territory }\end{array}$} & HPPI $\rightarrow$ ORBPPI & 15.59 & 0.05 & $Y$ \\
\hline & $\mathrm{HPPI} \rightarrow \mathrm{NRBPPI}$ & 20.58 & 0.01 & $Y$ \\
\hline & ORBPPI $\rightarrow \mathrm{HPPI}$ & 23.76 & 0.00 & Y \\
\hline & ORBPPI $\rightarrow$ NRBPPI & 32.40 & 0.01 & $Y$ \\
\hline & $\mathrm{NRBPPI} \rightarrow \mathrm{HPPI}$ & 20.56 & 0.01 & $Y$ \\
\hline & NRBPPI $\rightarrow$ ORBPPI & 33.44 & 0.00 & Y \\
\hline \multirow{6}{*}{$\begin{array}{c}\text { Australian } \\
\text { Capital } \\
\text { Territory }\end{array}$} & HPPI $\rightarrow$ ORBPPI & 19.03 & 0.03 & $Y$ \\
\hline & $\mathrm{HPPI} \rightarrow \mathrm{NRBPPI}$ & 19.18 & 0.02 & $Y$ \\
\hline & ORBPPI $\rightarrow$ HPPI & 5.52 & 0.79 & $\mathrm{~N}$ \\
\hline & ORBPPI $\rightarrow$ NRBPPI & 14.23 & 0.11 & $\mathrm{~N}$ \\
\hline & NRBPPI $\rightarrow$ HPPI & 4.86 & 0.85 & $\mathrm{~N}$ \\
\hline & $\mathrm{NRBPPI} \rightarrow$ ORBPPI & 8.21 & 0.51 & $\mathrm{~N}$ \\
\hline
\end{tabular}

Table 4: Granger causality tests of construction output PPI in Australia

Liu, J and London, K A (2010) 'Convergence among the sub-markets in Australian regional building construction sector', Australasian Journal of Construction Economics and Building, 10 (4) 11-33 
New South Wales:

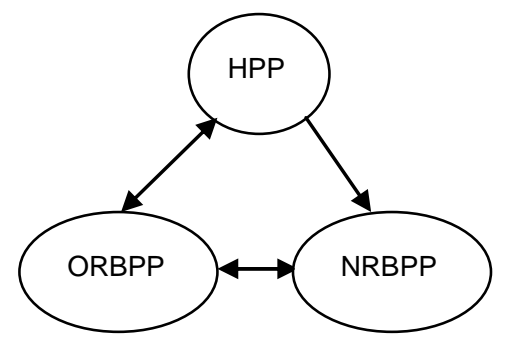

Queensland:

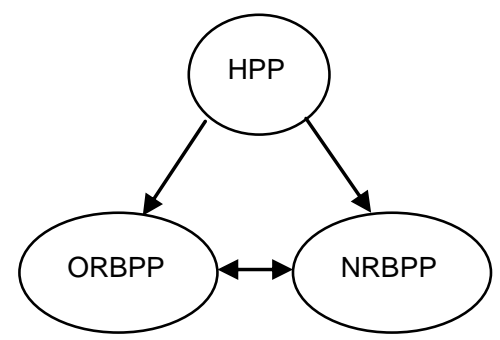

Western Australia:

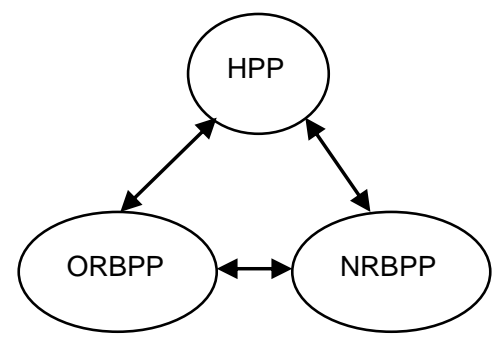

Northern Territory:

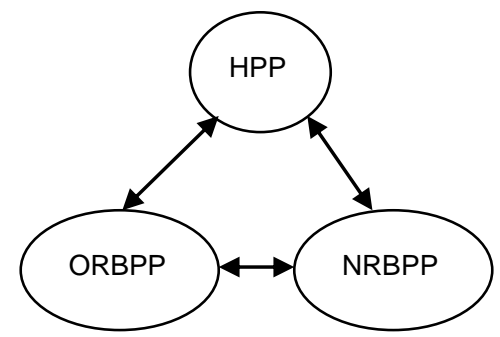

Victoria:

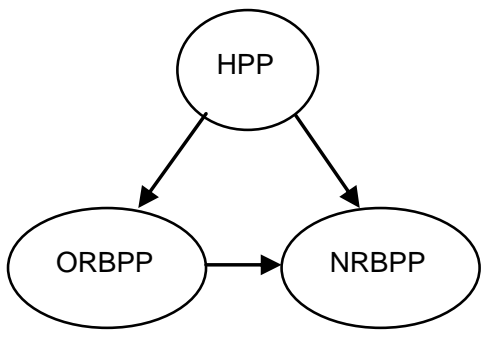

South Australia:

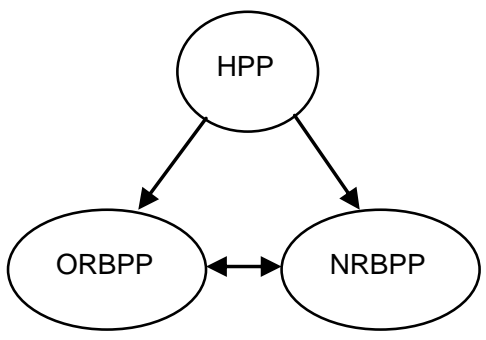

Tasmania:

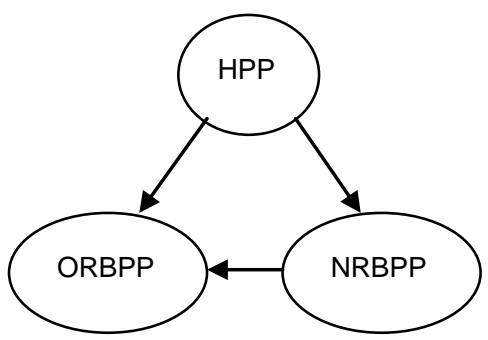

Australian Capital Territory:

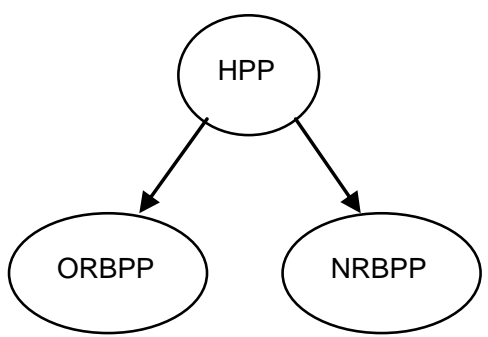

Figure 4: Causal relationships between prices of construction markets in Australia

Secondly, not only do Granger causality exist in between two dwelling (house and otherresidential building) construction markets, but also movements in the prices of the dwelling constructions can spread into the other construction markets of building construction sector non-residential building construction market. The results suggest that house construction prices Granger cause non-residential building construction prices in all Australian states. In addition, the construction prices of other-residential building construction markets also perform well in the Granger causality test associated with non-residential building 
construction markets. The other-residential building construction prices Granger cause the non-residential building construction prices in New South Wales, Victoria, Queensland, South Australia, Western Australia, and Northern Territory. Besides, the final causal linkage identified amongst these three construction markets is that the changes in construction prices of non-residential building construction markets Granger cause the price variations of other-residential building construction markets in most of states except Victoria and Australian Capital Territory. Nevertheless, there is no causal relationship within the direction from non-residential building construction market to house construction market.

The Granger causality test has examined the direct causal relationships between different kinds of construction markets in Australia. However, it can not trace out the dynamic response of one construction market to the shocks of the other markets. For this purpose, the GIRF will be utilised to analyze the sensitivity of one market to the standard deviation shocks of others.

Figure 5 indicates the accumulated response results of three construction markets in each state in Australia. Firstly, in all of the figures, a standard deviation of house construction price itself will result in positive increases in future house construction prices in every state. This situation also can be found in other two construction markets, indicating that the impulses of the other-residential building construction prices and non-residential building construction prices will positively affect the future price levels of themselves. The possible reason is that current changes in prices or costs related to building constructions affect the short-run expectations of resource suppliers (e.g. materials and labour) in the construction industry.

Secondly, as mentioned previously, changes in house construction output PPI Granger cause the movement in other-residential construction output PPI and non-residential construction output PPI in six states and two territories in Australia. The results of the GIRF presented in Figure 5 further indicate that increases in the output prices of house construction effectively lead to positive movements in construction output prices of other two construction markets in Australia. The fluctuations of the responses of the ORBPPI and the NRBPPI to the standard deviation of the HPPI are more identifiable in Victoria, where the accumulated responses of such two variables (ORBPPI and NRBPPI) keep going up by $30 \%$ and $20 \%$ following the standard deviation of the HPPI. In Queensland, South Australia, and Northern Territory, the levels of the responses of the ORBPPI and the NRBPPI to the impulse of the HPPI are similar, ranging from $16 \%$ to $19 \%$ in 10 quarters. Moreover, in the cases of other states, involving New South Wales, Western Australia, Tasmania and Australian Capital Territory, the accumulated responses of the ORBPPI and the NRBPPI to the standard deviation of the HPPI are less sensitive than that of other four states. The maximum values of such responses stay in the intervals from $2.0 \%$ to $7.6 \%$ $(\mathrm{HPPI} \rightarrow \mathrm{ORBPPI})$ and $1.0 \%$ to $6.1 \%(\mathrm{HPPI} \rightarrow \mathrm{NRBPPI})$. The smallest responsiveness of the ORBPPI and the NRBPPI appear in Western Australia, in which only $2.0 \%$ and $1.0 \%$ of positive movements of the ORBPPI and the NRBPPI are triggered by the standard deviation of the HPPI.

Liu, J and London, K A (2010) 'Convergence among the sub-markets in Australian regional building construction sector', Australasian Journal of Construction Economics and Building, 10 (4) 11-33 
Thirdly, the figures following show that standard deviation originated from the ORBPPI strengthens the increase trends of the HPPI in all states. In Queensland, Northern Territory, and Victoria, an accumulative total of about $13 \%$ increase in the HPPI is produced by the standard deviation of the ORBPPI in 10 quarters. Although the accumulated response of the HPPI to the standard deviation of the ORBPPI in Western Australia is less sensitive, it is still evident reaching $9.4 \%$ within 10 quarters. However, in New South Wales, the maximum values of the response of the HPPI to the standard deviation of the ORBPPI are the smallest, only $1.98 \%$ in 10 quarters. In the rest of other three states (Australian Capital Territory, South Australia, and Tasmania), the maximum values of the responses of the HPPI to the impulses of the ORBPPI range from $2.6 \%$ to $9.3 \%$. Furthermore, the dynamic impact of other-residential building construction on non-residential building construction is evident as well. In summary, increases in the construction output prices in other-residential building construction market have a positive effect on non-residential building construction markets in Australia. In the states where these two kinds of market have causal relationships, including New South Wales, Victoria, Queensland, South Australia, Western Australia, and Northern Territory, the accumulated responses of the NRBPPI to the impulses of the ORBPPI are dramatic, ranging from 6.8\% (New South Wales) to 21\% (Queensland and Northern Territory).

Finally, apart from the dynamic effects caused by two dwelling construction markets, the positive impact of non-residential building construction has also been identified. Figure 5 shows that in all Australian states increases in non-residential construction prices drive up the construction price levels of the house and other-residential building construction markets. Influenced by the NRBPPI, the increase trends of the HPPI in Victoria and Western Australia are strengthened by $14 \%$ and $17 \%$ while in New South Wales, South Australia and Australian Capital Territory only $3.1 \%, 2.7 \%$, and $1.9 \%$ of positive changes in the HPPI have been triggered. Additionally, the responsiveness of the HPPI to the standard deviation of the NRBPPI in Queensland, Tasmania and Northern Territory has similar performances approximate $10 \%$ of positive responses. Regarding the impact of NRBPPI on otherresidential building construction, the accumulated responses of the ORBPPI in Victoria (22.9\%), Queensland (14.9\%), Western Australia (13\%), and Northern Territory (15.5\%) are sensitive. However, in other four states, the values of the responses are much less, ranging from $4.0 \%$ to $7.9 \%$ within 10 quarters.

According to the Granger causality test and the GIRF, the appreciations in construction output prices of dwelling construction markets Granger cause and positively influence the output prices of non-residential building construction market in Australia. The possible reason is an increasing demand for housings caused by population growth or rise in personal income in Australia. The positive change in housing demand is definitely an important dynamics for house prices. Theoretically, house price is an activator of new housing construction (Quigley, 1998). Thus, the level of new housing construction is stimulated up by the inflation of house prices in Australia, causing an increasing demand for building materials and construction labours. As a result, the prices of the building materials and the labour wages can be dramatically driven up when the supply of materials and labour

Liu, J and London, K A (2010) 'Convergence among the sub-markets in Australian regional building construction sector', Australasian Journal of Construction Economics and Building, 10 (4) 11-33 
stays in a relative level. It is knowledge that the construction labour and most of building materials employed in the dwelling construction markets are utilised in non-residential building construction markets as well. So the construction output prices of non-residential building construction are gradually enhanced following the increases in output prices of house and other-residential building construction markets. Moreover, the positive changes in non-residential building construction markets have positive impact on house and otherresidential construction markets in all states in Australia. This is possibly due to the urban growth initialed by the increases in housing stocks via new housing constructions. This growth may create a lot of new residential districts from existing metropolitan areas to rural areas. These new suburbs provide business developers with an opportunity to make investment in non-residential building constructions, such as schools, hospitals, and shopping malls, owing to a huge demand for necessary living facilities. The perfection of such facilities can positively contribute on the housing prices of the new residential districts because the quantities and qualities of public amenities (e.g. schools, hospitals, shopping malls, and churches) are the major determinants of house prices (Sirmans et al., 2005). Therefore, the local construction levels of new houses and other-residential buildings are raised again, and then the construction output price will also be positively affected.

New South Wales:
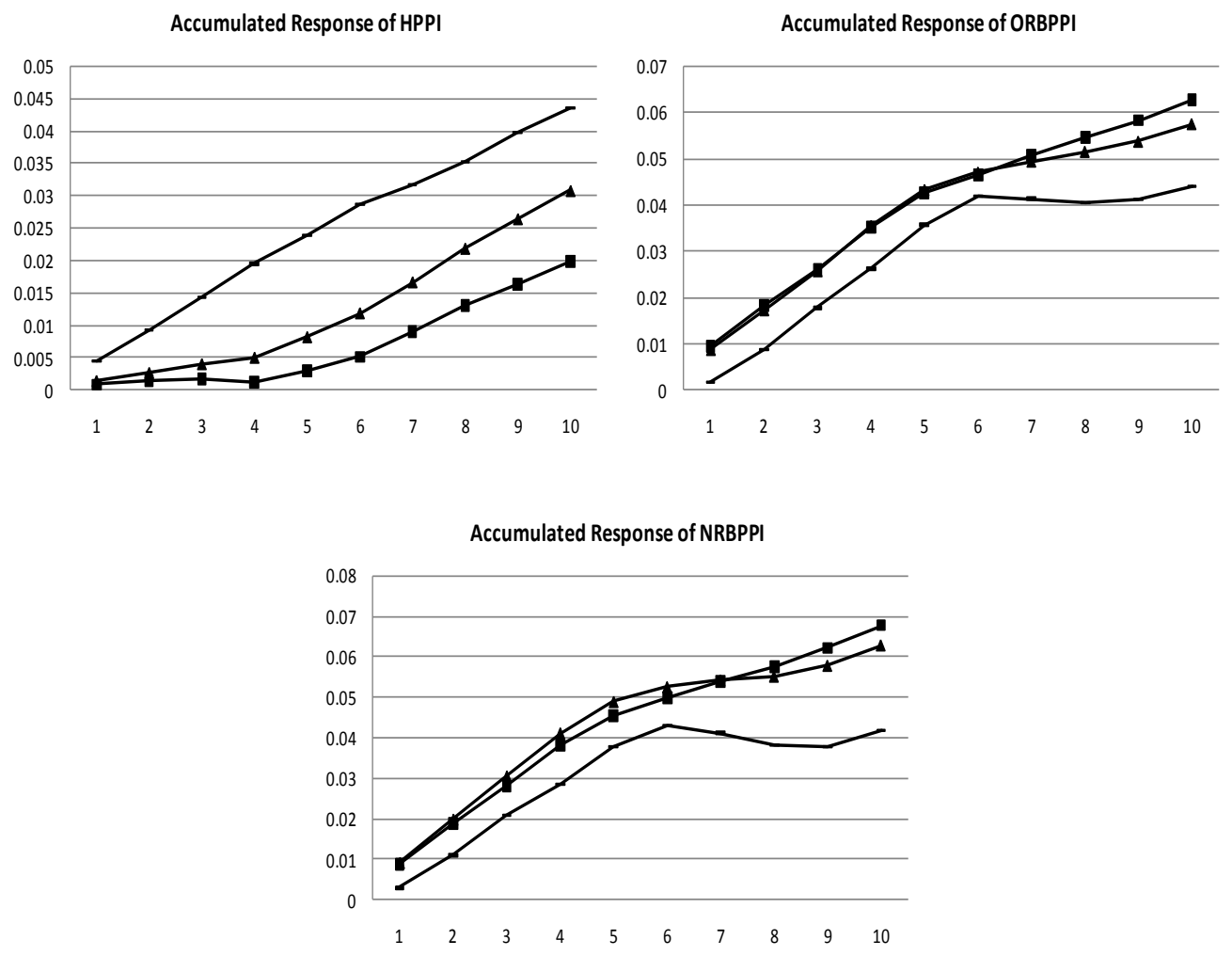

Liu, J and London, K A (2010) 'Convergence among the sub-markets in Australian regional building construction sector', Australasian Journal of Construction Economics and Building, 10 (4) 11-33 
Australasian Journal of Construction Economics and Building

\section{Victoria:}
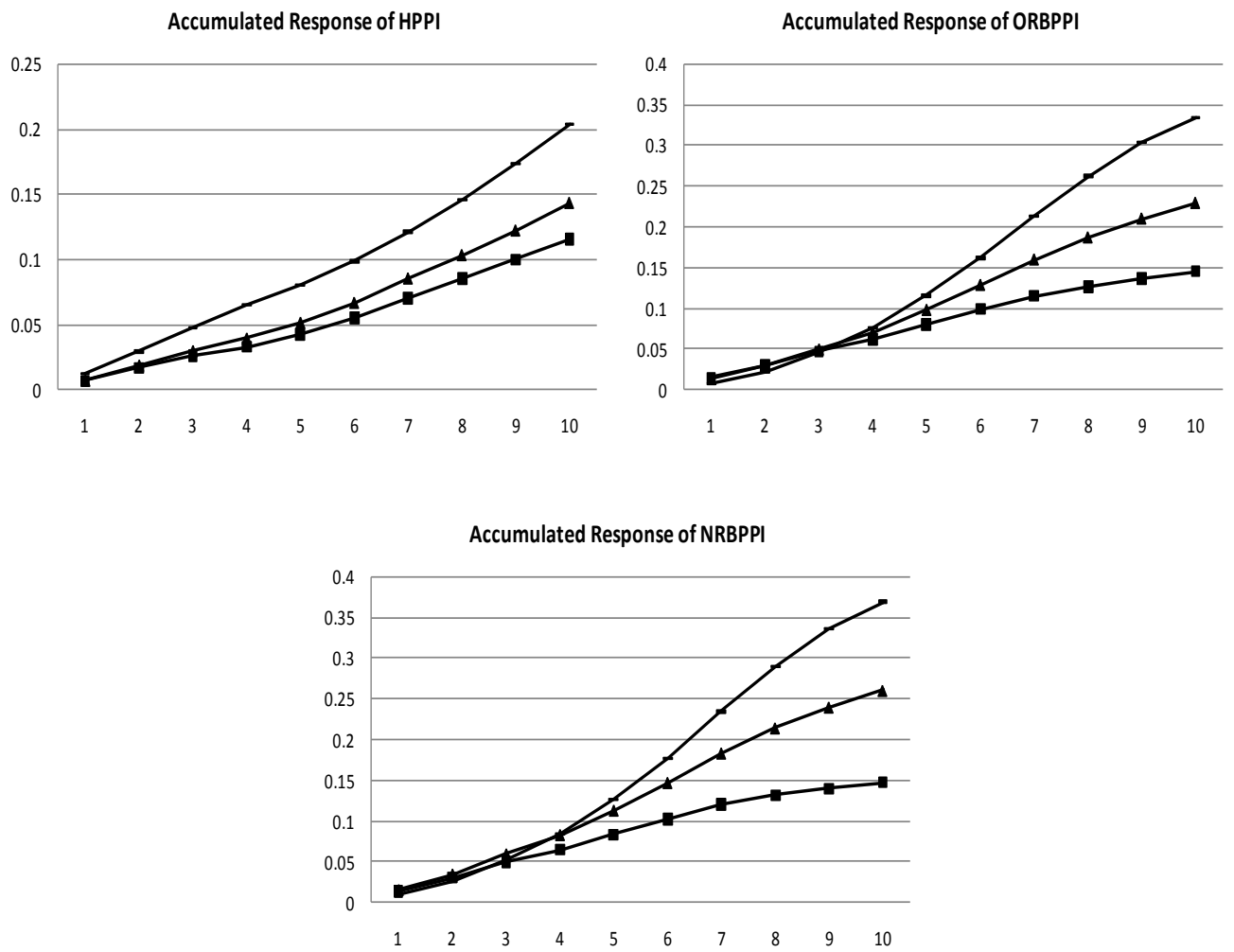

\section{Queensland:}
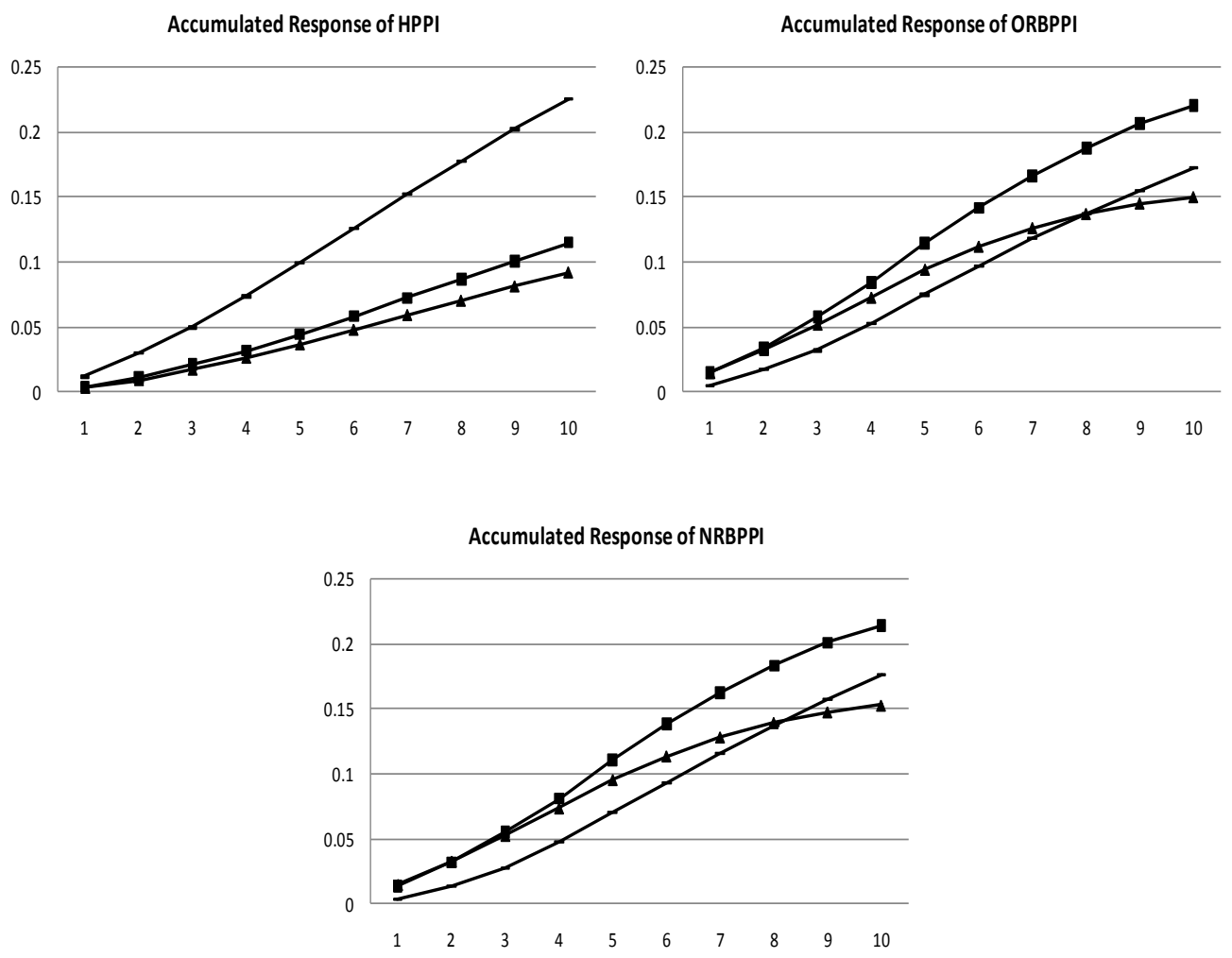

Liu, J and London, K A (2010) 'Convergence among the sub-markets in Australian regional building construction sector', Australasian Journal of Construction Economics and Building, 10 (4) 11-33 


\section{South Australia:}
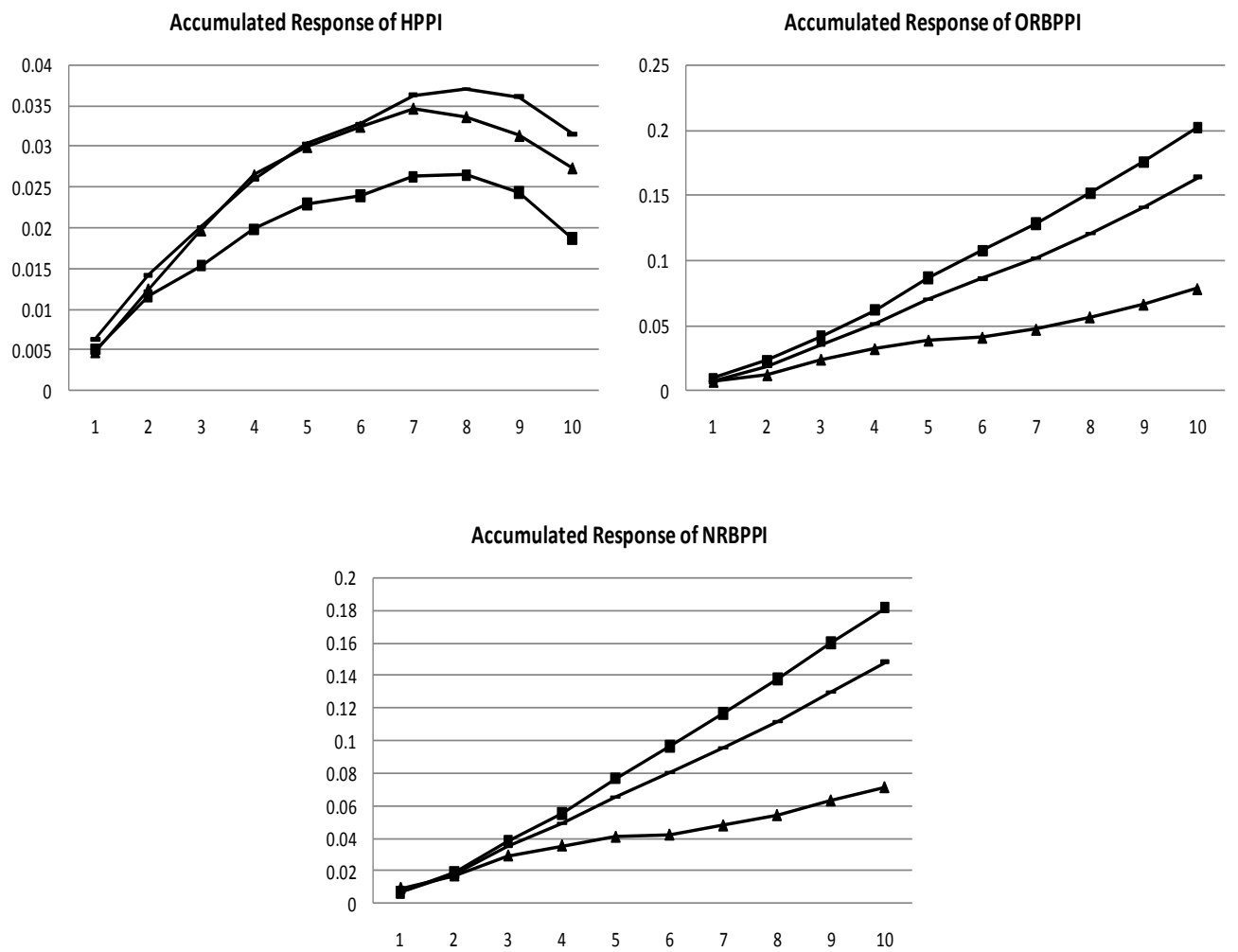

Western Australia:
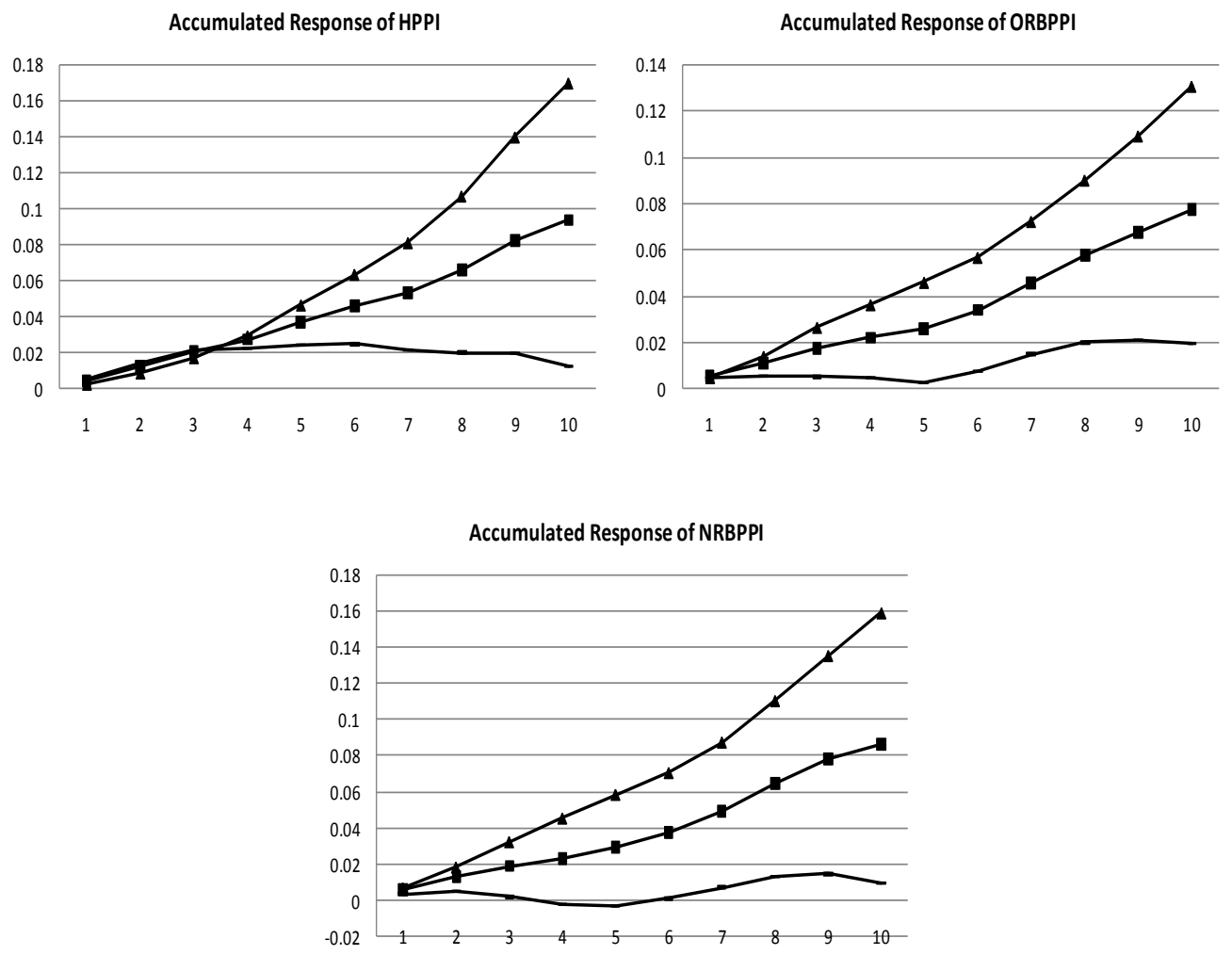

Liu, J and London, K A (2010) 'Convergence among the sub-markets in Australian regional building construction sector', Australasian Journal of Construction Economics and Building, 10 (4) 11-33 
Australasian Journal of Construction Economics and Building

\section{Tasmania:}
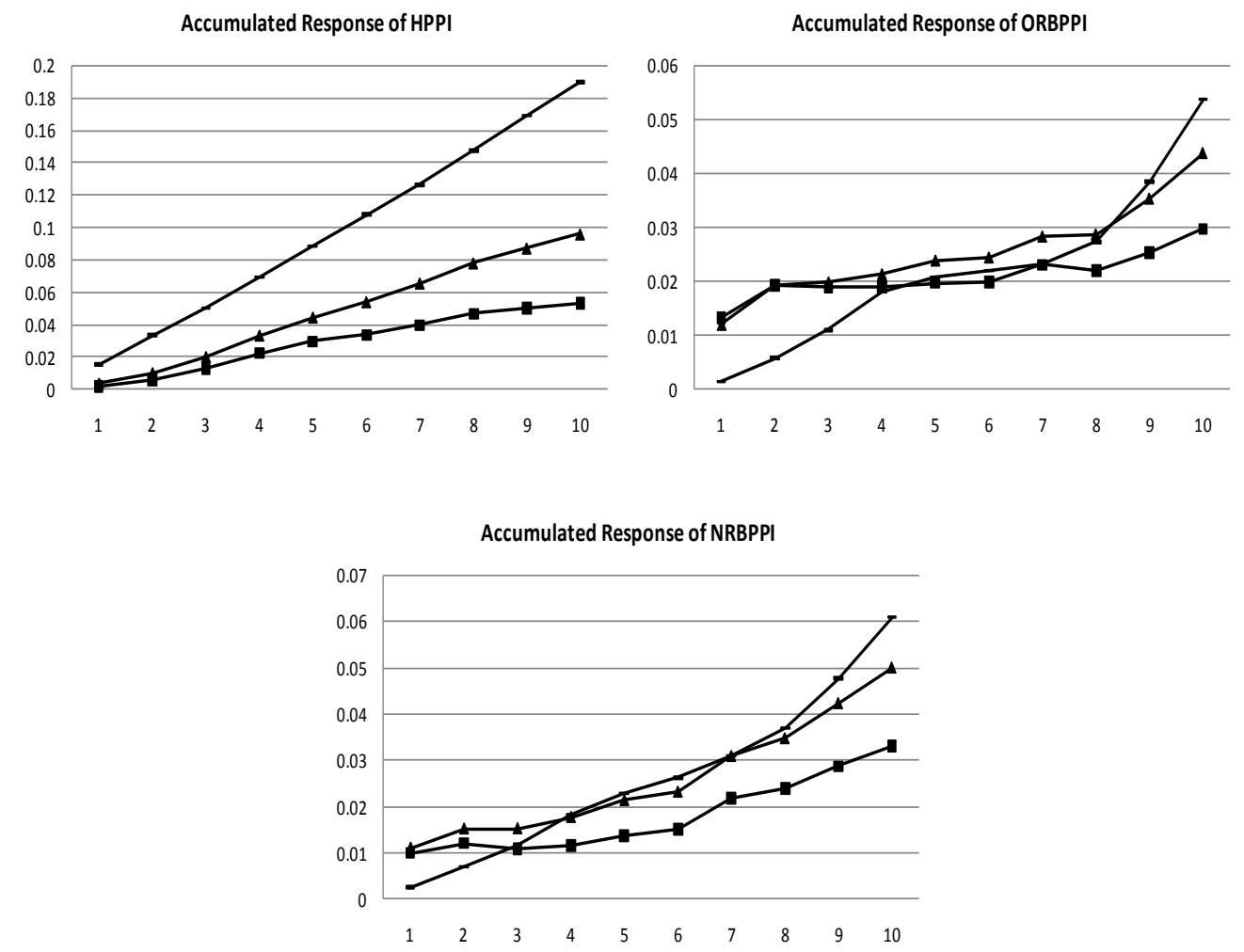

Northern Territory:
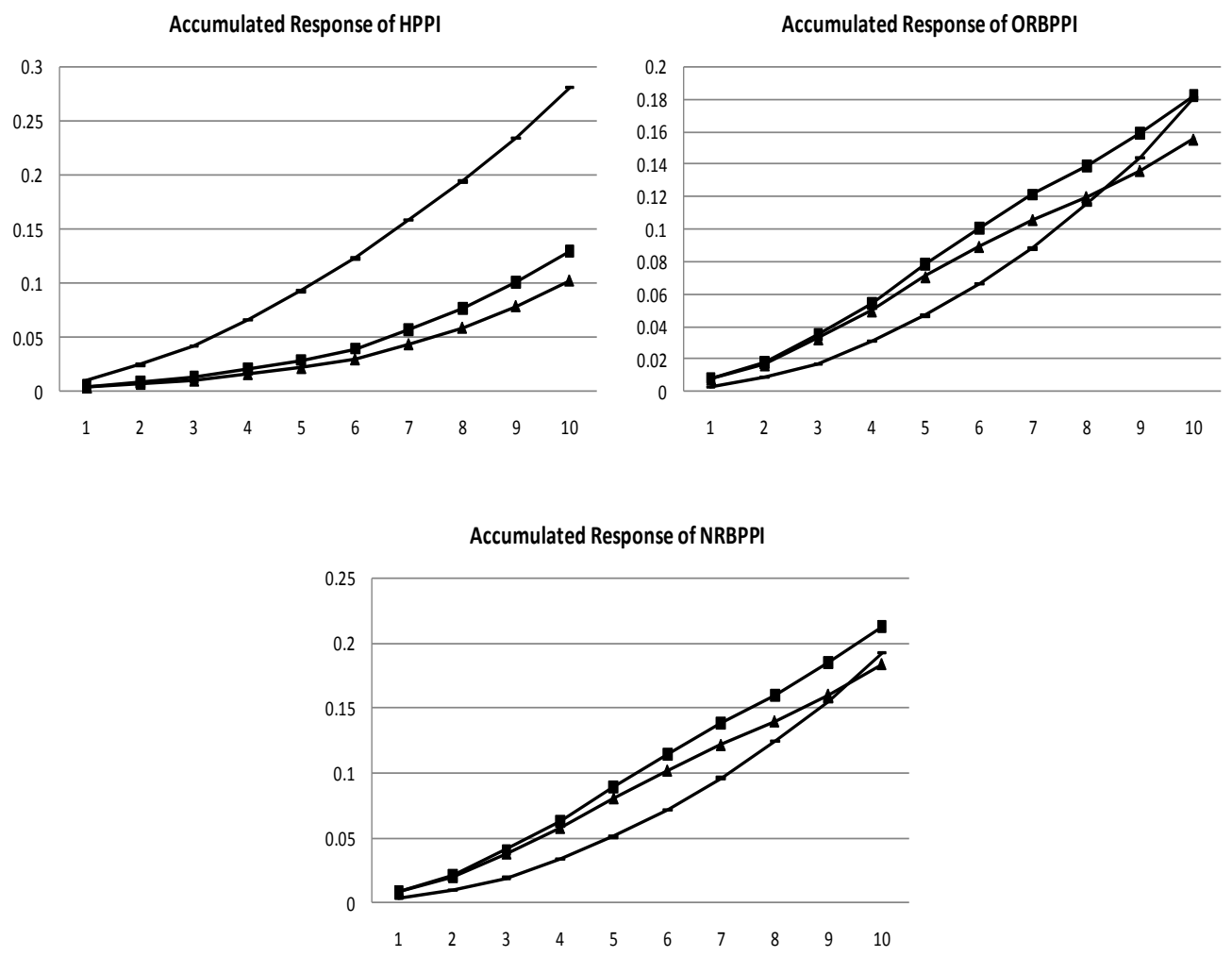

Liu, J and London, K A (2010) 'Convergence among the sub-markets in Australian regional building construction sector', Australasian Journal of Construction Economics and Building, 10 (4) 11-33 
Australian Capital Territory:
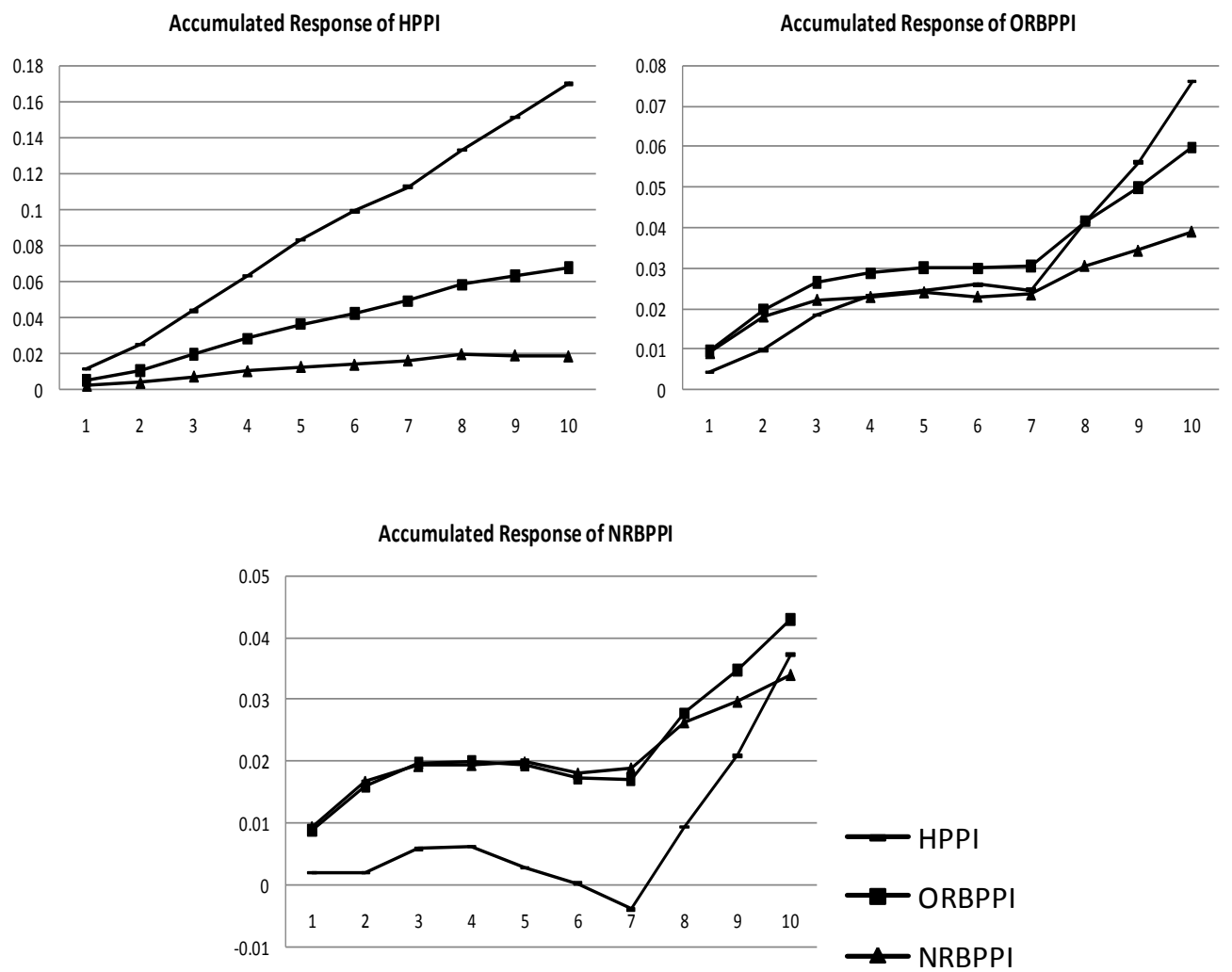

Figure 5: Accumulated response of HPPI, ORBPPI, and NRBPPI

\section{Conclusion}

This study empirically examined the cross-market interactions of construction prices between three types of construction markets within building construction sector in eight states of Australia during the period of 1998Q1 to 2010Q1. Benefited by the Granger causality test and generalised impulse response function, the causal and dynamic relationships of construction industry output producer price indexes between house construction market, other-residential building construction market and non-residential building construction market have been identified. In summary, there are several one-way and bilateral causal relationships amongst the three kinds of construction markets. The performance of house construction market is dramatic and its construction prices Granger cause the changes in the prices of other two construction markets. However, there is no price causal relationship in the direction from non-residential building construction market to house construction market. Moreover, increases in construction prices in each construction market positively influence the price level of other two markets, particularly in Victoria, Queensland, Western Australia, and Northern Territory, where the response of each construction market to the standard deviation shocks of other construction markets are more sensitive. The outcomes of this paper not only empirically support the theoretical perspective that construction prices are not independent but interconnected in different kinds of construction markets, but also provide construction enterprises and policy makers with valuable information to perform well in business operations and market regulations in Australia. 


\section{References}

ABS (2005) Construction industry output price indexes, available at: http://www.abs.gov.au/AUSSTATS/abs@.nsf/DSSbyCollectionid/63B1F55C25621179CA25 6ED200796D3E (accessed 08 June 2010)

ABS (2006) Australian and New Zealand Standard Industrial Classification: Building construction, available at: http//: www.abs.gov.au/AUSSTATS/abs@.nsf/Latestproducts/ A7E2AD0B2E92A75FCA25711F00146DDB?OpenDocument (accessed 08 June 2010)

ABS (2010a) Producer price indexes, Australia: Explanatory notes, available at: http://www.abs.gov.au/AUSSTATS/abs@.nsf/Lookup/6427.0Explanatory\%20Notes1Mar\%20 2010?OpenDocument (accessed 10 June 2010)

ABS (2010b) Producer price indexes, Australia: Selected output of division E construction, group and class index numbers, available at: http://www.abs.gov.au/AUSSTATS/abs@.ns $\mathrm{f} /$ DetailsPage/6427.0Mar\%202010?OpenDocument (accessed 10 June 2010)

Ashworth, J. \& Parker, S. C. (1997) 'Modelling regional house prices in the UK', Scottish Journal of Political Economy, 44 (3), 225 - 246

Bramley, G., Leishman, C. \& Watkins, D. (2008) 'Understanding neighbourhood housing markets: Regional context, disequilibrium, sub-markets and supply', Housing Studies, 23 (2), $179-212$

Chien, M. S. (2010) 'Structural breaks and the convergence of regional house prices', Journal of Real Estate Finance and Economics, 40 (1), 77 - 88

Cook, S. (2003) 'The convergence of regional house prices in the UK', Urban Studies, 40 (11), $2285-2294$

Cook, S. (2005) 'Detecting long-run relationship in regional house prices in the UK', International Review of Applied Economics, 19 (1), 107 - 118

Drake, L. (1995) 'Testing for convergence between UK regional house prices', Regional Studies, 29 (4), 357 - 366

Engle, R. F. \& Granger, C. W. J. (1987) 'Co-integration and error correction: Representation, estimation, and testing', Econometrica, 55 (2), 251 - 276

Engle, R. F. \& Yoo, B. S. (1987) 'Forecasting and testing in co-integrated systems', Journal of Econometrics, 35 (1), $143-159$

Gao, T. M. (2009) Quantitative Economics, Tsinghua University Press, Beijing

Giussani, B. \& Hadjimatheou, G. (1991) 'Modelling regional house prices in the United Kingdom', Papers in Regional Science, 70 (2), $201-219$

Granger, C. W. J. (1969) 'Investigating causal relations by econometric models and crossspectral methods', Econometrica, 37 (3), $424-438$

Greene, W. (2000) Econometric analysis, 4th Edn., Prentice-Hall, New Jersey

Hui, E. C. M. \& Yue, S. (2006) 'Housing price bubbles in Hong Kong, Beijing and Shanghai: A comparative study', Journal of Real Estate Finance and Economics, 33 (4), 299 - 327 
Ho, L. S., Ma, Y. \& Haurin, D. R. (2008) 'Domino effects within housing market: The transmission of house price changes across quality tiers', Journal of Real Estate Finance and Economics, 37 (4), 299 - 316

Holmes, M. J. (2007) 'How convergence are regional house prices in the United Kingdom? Some new evidence from panel data unit root testing', Journal of Economic and Social Research, 9 (1), 1 - 17

Holmes, M. J. \& Grimes, A. (2007) 'Is there long-run convergence among regional house prices in the UK?', Urban Studies, 45 (8), 1531 - 1544

Jiang, H., Fu, C. J. \& Liu, C. (2010) Investigating relationships of construction prices in Australia using cointegration analysis, Proceedings of 35th Australasian Universities Building Education Association (AUBEA) Conference, The University of Melbourne, Australia

Johansen, S. \& Juselius, K. (1990) 'Maximum likelihood estimation and inference on cointegration: With application to the demand for money', Oxford Bulletin of Economics and Statistics, 52 (2), $169-210$

Koop, G., Pesaran, M. H., \& Potter, S. M. (1996) 'Impulse response analysis in nonlinear multivariate models', Journal of Econometrics, 74 (1), $119-147$

Liu, C., Ma, L., Luo, Z. Q. \& Picken, D. (2009) 'An independence analysis of Australian house prices using variance decomposition', International Journal of Housing Markets and Analysis, 2 (3), 218 - 232

Liu, C., Luo, Z. Q. \& Picken, D. (2008) 'Identifying house price diffusion patterns among Australian state capital cities', International Journal of Strategic Property Management, 12 (4), $237-250$

Luo, Z. Q., Liu, C. \& Picken, D. (2007) 'Housing price diffusion pattern of Australia's state capital cities', International Journal of Strategic Property Management, 11 (4), 227 - 242

Meen, G. (1996) 'Spatial aggregation, spatial dependence and predictability in the UK housing market', Housing Studies, 11 (3), 345 - 373

Meen, G. (1999) 'Regional house prices and the ripple effect: A new interpretation', Housing Studies, 14 (6), 733 - 753

Muellbauer, J. \& Murphy, A. (1997) 'Booms and bursts in the UK housing market, The economic Journal, 107 (441), 1701 - 1727

Munro, M. \& Tu, Y. (1996) UK house price dynamics: Past and future trends - A technical paper, Council of Mortgage Lenders, London

Quigley, J. M. (1999) 'Real estate prices and economic cycles', International Real Estate Review, 2 (1), 1 - 20

Rajaguru, G. \& Abeysinghe, T. (2008) 'Temporal aggregation, cointegration and causality inference', Economics Letters, 101 (3), 223 - 226

Sirmans, G. S., Macpherson, D. A. \& Zietz, E. N. (2005) 'The composition of hedonic pricing models', Journal of Real Estate Literature, 13 (1), 3 - 43 
Skitmore, M., Runeson, G. \& Chang, X. (2006) 'Construction price formation: full-cost pricing or neoclassical microeconomic theory?', Construction Management and Economics, 24 (7), $773-783$

Stevenson, S. (2004) 'House price diffusion and inter-regional and cross-border house price dynamics', Journal of Property Research, 21 (4), 301 - 320

Toda, H. Y. \& Yamamoto, T. (1995) 'Statistical inference in vector autoregressions with possibility integrated process', Journal of Econometrics, 66 (1-2), 225 - 250

Yamamoto, T. \& Kurozumi, E. (2006) 'Test for long-run Granger non-causality in cointegrated system', Journal of Time Series Analysis, 27 (5), 703 - 723 